Personalidade Acadêmica Homenageada:

Florisbal de Souza Del'OImo (Professor Convidado - UNICURITIBA)

\title{
HÁ PRIVACIDADE NA SOCIEDADE DA INFORMAÇÃO? UMA ANÁLISE À LUZ DO PRINCÍPIO DA DIGNIDADE HUMANA E DAS REDES SOCIAIS
}

\section{IS PRIVACY IN THE INFORMATION SOCIETY? AN ANALYSIS BY THE PRINCIPLE OF HUMAN DIGNITY AND SOCIAL NETWORKS}

\section{CARINA PESCAROLO}

Mestranda em Direito e Cidadania no Centro Universitário Curitiba - UNICURITIBA.

MARINA ZAGONEL Mestranda em Direito e Cidadania no Centro Universitário Curitiba - UNICURITIBA.

\section{RESUMO}

Partindo do notório avanço da tecnologia e do crescente uso das redes sociais para os mais variados fins na sociedade da informação, a presente pesquisa busca analisar em que medida a informação, referente a um indivíduo ou os dados por ele fornecidos nos mais variados domínios virtuais, podem ser livremente difundidos na rede mundial de computadores. Para tanto, analisam-se os conceitos de dignidade humana e os direitos da personalidade como elementos balizadores das condutas virtuais, tanto na internet quanto nas redes sociais.

PALAVRAS-CHAVES: Sociedade da Informação; Redes Sociais; Dignidade Humana; Direitos da Personalidade. 


\section{Personalidade Acadêmica Homenageada:}

Florisbal de Souza Del'Olmo (Professor Convidado - UNICURITIBA)

\section{ABSTRACT}

Starting from the notorious advancement of technology and the increasing use of social networks for the most varied purposes in the information society, the present research seeks to analyze to what extent the information, referring to an individual or the data provided by him in the most varied virtual domains, can be freely disseminated on the world wide web. For that, the concepts of human dignity and personality rights are analyzed as guiding elements of virtual behaviors, both on the Internet and in social networks.

KEYWORDS: Information Society; Social Networks; Human Dignity; Rights of the Personality.

\section{INTRODUÇÃO}

Em decorrência das constantes transformações tecnológicas, a internet ganhou espaço e contornos nas interações sociais. Cria-se um amplo espaço para manifestação de opinião e, ao mesmo tempo, tem-se uma nova extensão das esferas individuais da vida.

A sociedade da informação, conceituada como uma nova forma de organização social, política e econômica utiliza-se maciçamente da tecnologia para os mais diversos afazeres, ocasionando, não raras vezes, o distanciamento dos próprios indivíduos que optam por manter seus laços sociais de maneira virtual.

Considerando a amplitude da rede mundial de computadores (internet) e a dificuldade em controlar as informações prestadas e transmitidas pelos usuários, surge o grande desafio da atualidade: manter intactos os direitos fundamentais e a dignidade humana em um ambiente virtual sem barreiras claras.

O presente estudo busca refletir em que medida a liberdade de expressão na sociedade da informação e o uso de dados fornecidos pelos usuários podem ser indistintamente utilizados. Para tanto, por meio de uma metodologia dedutiva e 


\section{Personalidade Acadêmica Homenageada:}

Florisbal de Souza Del'Olmo (Professor Convidado - UNICURITIBA)

coleta de material bibliográfico far-se-á, em um primeiro momento, uma análise a respeito do princípio da dignidade humana, buscando compreender a necessidade de ser resguardada também no ambiente virtual.

Em um segundo momento parte-se para a análise dos direitos da personalidade, pois têm papel de destaque no ordenamento, na medida em que pertencem ao indivíduo desde a sua concepção. Deste modo, o Estado não pode abster-se de protegê-los, devendo exercer medidas a fim de mantê-los intocáveis.

A recente Lei 13.709, de 14 de agosto de 2018, a qual alterou o marco civil da internet, traz em seus dispositivos os direitos ora tratados como fundamentos indissociáveis da proteção de dados na sociedade da informação, trazendo à tona a relevância do estudo ora proposto.

Por fim, busca-se demonstrar a importância dos avanços da internet na sociedade da informação e como o uso das redes sociais forma uma relação tênue entre a dignidade e os direitos fundamentais, o que justifica a tutela pelo Estado deste ambiente e do modus operandi dos usuários na rede.

\section{DIGNIDADE HUMANA NA SOCIEDADE DA INFORMAÇÃO}

Antes de se adentrar ao tema central objeto da presente pesquisa, faz-se necessário compreender a importância do princípio da dignidade humana e dos direitos da personalidade no ordenamento jurídico brasileiro e, consequentemente, sua tutela na sociedade da informação.

Vivemos em uma sociedade que se encontra em constante transformação. Entretanto, ainda que as informações e a exposição individual aconteçam em um ambiente virtual de fácil acesso, tem-se que a dignidade humana e os direitos fundamentais devem estar sempre em evidência.

Tal assunto tem se mostrando em constante estudo, tendo em vista os abalos aos domínios da vida, ocasionados pela interação social no ambiente virtual, sem qualquer barreira. 


\section{Personalidade Acadêmica Homenageada: \\ Florisbal de Souza Del'Olmo (Professor Convidado - UNICURITIBA)}

Do mesmo modo que as sociedades evoluem, os direitos nelas existentes também passam por mudanças constantes e conceituais com o decorrer do tempo. Liga-se o conceito de "direitos" às pessoas que deles serão titulares. Alguns destes privilégios são inerentes ao homem desde o seu surgimento, outros estão diretamente ligados ao convívio coletivo. Na visão de Bobbio (1992, p. 4):

\footnotetext{
Os direitos nascem quando devem ou podem nascer. Nascem quando o aumento do poder do homem sobre o homem cria novas ameaças à liberdade do indivíduo ou permite novos remédios para as suas indigências: ameaças que são enfrentadas através de demandas de limitação de poder; remédios que são providenciados através da exigência de que o mesmo poder intervenha de modo protetor.
}

Assim como o nascimento dos direitos, a sua tutela deve estar intimamente ligada às transformações sofridas pela sociedade, a fim de que não se tenha um conceito obsoleto sem qualquer resguardo pelo Direito vigente.

\subsection{DIREITOS HUMANOS OU DIREITOS FUNDAMENTAIS?}

O surgimento de um Estado constitucional pode ser considerado o marco inicial do tema ora tratado. Buscava-se neste período privilegiar o lado individual do cidadão, e não apenas seus deveres para com o Poder (SARLET, 2010, p. 36). O neoconstitucionalismo, por sua vez, teve grande importância tanto para a positivação e defesa destas prerrogativas quanto para as normas já positivadas, visto que a Constituição passou a ingressar e ser considerada a base do sistema normativo (PAROSKI, 2008, p. 41).

O conceito de "direitos fundamentais" deriva dos direitos naturais defendidos pelo jusnaturalismo. Nesta concepção, ao nascer, o ser humano já é, por si só, titular de alguns direitos (direitos naturais); sendo esta considerada por Ingo Wolfgang Sarlet (2010, p. 38) a "pré-história" dos direitos fundamentais.

O processo de positivação de novas normas e deveres fez com que os direitos naturais fossem gradativamente incluídos nas legislações da época. Assim, deixaram de ser apenas um valor agregado ao homem em sua individualidade, para 


\section{Personalidade Acadêmica Homenageada: \\ Florisbal de Souza Del'Olmo (Professor Convidado - UNICURITIBA)}

serem aplicados no coletivo, beneficiando tanto aqueles hierarquicamente privilegiados como aqueles que antes eram tratados como seres "sem direitos".

É comum observar que os termos "direitos humanos" e "direitos fundamentais", por vezes, são utilizados como sinônimos. No entanto, apresentam singularidades que os tornam distintos entre si. Muito embora a titularidade de ambos seja a mesma, ou seja, o homem, isto não representa que têm a mesma definição doutrinária. Junto a estes dois termos comumente utilizados, estão os direitos naturais. Estes, que como já citado anteriormente, são considerados como a pré-história dos direitos fundamentais.

A principal diferença entre os direitos fundamentais e humanos encontra-se na esfera de sua aplicabilidade e proteção. Aqueles, para inúmeros autores ${ }^{1}$, correspondem aos direitos positivados em Constituições. Já estes, fazem parte e estão positivados em tratados e declarações de âmbito internacional. $O$ fato de os direitos fundamentais integrarem Cartas Magnas de diferentes países, faz com que cada Estado tenha suas próprias prerrogativas. O mesmo não ocorre com os direitos humanos, visto que têm aplicação para todas as nações.

No mais, Gisela Maria Bester (2005, p. 558), ao citar o doutrinador Pérez Luño, ensina que os direitos fundamentais integram o conceito de direitos humanos, pois estes são considerados mais amplos em relação àqueles. Os direitos fundamentais podem ser caracterizados por dois critérios formais. Serão assim considerados aqueles que estiverem em instrumentos constitucionais e, que receberem maior atenção quanto a sua garantia e segurança. (SCHIMITT, 205, p. 561) Ademais, não é correto afirmar que tais termos são independentes entre si:

[...] os direitos humanos guardam relação com uma concepção jusnaturalista (jusracionalista) dos direitos, ao passo que os direitos fundamentais dizem respeito a uma perspectiva positivista. Neste sentido, os direitos humanos [...] acabam sendo transformados em direitos fundamentais pelo modelo positivista, incorporando-os ao sistema de direitos positivo como elementos essenciais, visto que apenas mediante um processo de "fundamentalização" (precisamente pela incorporação às constituições), os direitos naturais e inalienáveis da pessoa adquirem a

${ }^{1}$ Cita-se a exemplo de autores que utilizam deste conceito: Ingo Wolfgang Sarlet, Gisela Maria Bester, Antonio-Enrique Pérez Luño e Paulo Bonavides. 


\section{Personalidade Acadêmica Homenageada: \\ Florisbal de Souza Del'Olmo (Professor Convidado - UNICURITIBA)}

hierarquia jurídica e seu caráter vinculante em relação a todos os poderes constituídos no âmbito de um Estado Constitucional (SARLET, 2010, p. 32).

Acima dos direitos humanos e fundamentais, estão os direitos naturais, e, dentre estes valores intrínsecos aos homens, está a dignidade humana, a qual "o distingue das demais criaturas, no sentido de que todos os seres humanos são dotados da mesma dignidade, noção esta que se encontra, por sua vez, intimamente ligada à noção da liberdade pessoal de cada indivíduo [...]”. (SARLET, 2006, p. 30)

Assim, necessário se faz a análise do princípio da dignidade humana, para os fins pretendidos nesta pesquisa.

\subsection{PRINCÍPIO DA DIGNIDADE HUMANA}

Além dos ideais greco-romanos ${ }^{2}$ e cristãos $^{3}$, o pensamento jusnaturalista também influenciou a concepção de dignidade humana. Immanuel Kant representou um marco para este assunto, pois seus ensinamentos e conceitos são utilizados até hoje. Segundo o filósofo, a dignidade é inerente ao homem, vez que apenas ele é considerado como um ser racional. A racionalidade é ponto importante para a definição do que é a dignidade, pois nos guia em nossas próprias escolhas e remete ao principal ideal kantiano de que o homem é um fim em si mesmo, devendo buscar a sua felicidade sem prejudicar o próximo. (SARLET, 2006, p. 33)

A principal diferença entre seres com ou sem racionalidade, encontra-se em seu valor. Seres irracionais (coisas) possuem um preço, que pode ser substituído. No entanto, seres racionais (homem) possuem dignidade.

O fato de ser considerada como um valor irrevogável pertencente ao homem faz com que a dignidade esteja posicionada em lugar de destaque nas esferas do conhecimento e seja considerada como norte para as condutas humanas ao longo

\footnotetext{
${ }^{2}$ Neste período surge a "ideia de um homem com validade universal e normativa" (MARTINS, 2006, p. 21), a qual passou nortear a noção de dignidade que temos hoje. Em sentido um pouco diverso, o povo romano tratava tal tema como sendo um "status" social relativo à uma função pública. Deste modo, aqueles que a exerciam deveriam ser tratados com o máximo respeito pelos demais.

${ }^{3} \mathrm{O}$ ideário cristão foi o que mais influenciou na formação de um conceito ao tema ora tratado. Para o cristianismo o homem não pode ser tido como um objeto e consequentemente nem os valores que a ele são atribuídos, visto que representa a imagem e semelhança de Deus.
} 


\section{Personalidade Acadêmica Homenageada:}

Florisbal de Souza Del'Olmo (Professor Convidado - UNICURITIBA)

da história. O jurista Sarlet (2006, p. 37) aduz que a partir do momento que uma ordem constitucional proclama o ideal da dignidade, ela invariavelmente acaba por considerar que os seus titulares possuem direitos intrínsecos.

Assim, em uma análise conjunta aos conceitos que foram surgindo ao passar dos anos, com a contribuição de vários pensadores ${ }^{4}$, tem-se que a dignidade é um valor inerente ao homem racional, ou seja, um atributo da pessoa humana. (AMARAL, 2008, p. 74)

Contudo, "apresenta-se como um standard jurídico, no sentido de que é modelo sem significado preciso, de conteúdo indeterminado [...]" (AMARAL, 2008, p. 72). Para Rizzatto Nunes (2002, p. 49), simplifica-se esta definição a partir do momento que se reconhece que a dignidade nasce com o homem, e por esta razão será inerente à sua essência.

Destarte, como os direitos naturais, a dignidade humana foi igualmente inserida no direito positivo e elevada a princípio fundamental e norteador do constitucionalismo brasileiro. Para Dinaura Godinho (2005, p. 21) "a dignidade da pessoa humana não é, nem nunca foi, uma criação constitucional, mas um dado preexistente a toda a experiência especulativa, razão por que, no âmbito do Direito, só o ser humano é centro de imputação jurídica [...]".

Do mesmo modo que é difícil formular um único significado para o termo "dignidade humana", encontra-se esta mesma dificuldade para definir, de forma única, o que é o princípio da dignidade humana. $O$ fato de a dignidade ser considerada, assim como demonstrado anteriormente, um valor irrenunciável e pertencente ao homem em sua essência, é evidente que esta pode, e deve ser incansavelmente reconhecida e protegida, independente das transformações ocorridas na sociedade.

A valorização da dignidade pelo legislador a transformou em um princípio. De acordo com Rizzatto Nunes (2002, p. 19), os princípios possuem máxima importância em um sistema jurídico e de maneira alguma podem ser

\footnotetext{
${ }^{4}$ Dentre os pensadores que influenciaram na conceituação da dignidade humana, além de Kant, citase Thomas Hobbes, John Milton, Rousseau e Hugo Grócio.
} 


\section{Personalidade Acadêmica Homenageada: \\ Florisbal de Souza Del'OImo (Professor Convidado - UNICURITIBA)}

desconsiderados. "É ele que, como estrela máxima do universo ético-jurídico, vai sempre influir no conteúdo e alcance de todas as normas".

A utilização do conceito de dignidade nos textos legais deriva do surgimento de um novo Estado de Direito que luta em favor da democracia e visa transformar a sociedade utilizando-se dos instrumentos de proteção aos direitos fundamentais. Não apenas o indivíduo tem papel relevante para a conservação deste preceito (dignidade) em suas ações com seus pares, mas também o Estado. $O$ fato de ser reconhecida como inerente almeja medidas de preservação. Aduz Ingo Wolfgang Sarlet (2006, p. 47):

Como tarefa (prestação) imposta ao Estado, a dignidade da pessoa reclama que este guie as suas ações tanto no sentido de preservar a dignidade existente, quanto objetivando a promoção da dignidade, especialmente criando condições que possibilitem o pleno exercício e fruição da dignidade, sendo, portanto, dependente (a dignidade) da ordem comunitária [...].

As transformações ocorridas na sociedade, em especial o avanço das tecnologias e a facilidade de comunicação, criam novos desafios ao ordenamento jurídico, na medida em que se faz necessário encontrar o equilíbrio entre liberdade de expressão, dignidade e direitos fundamentais.

A recente Lei 13.709, de 14 de agosto de 2018, a qual alterou o marco civil da internet ${ }^{5}$, dispõe em seu artigo $2^{\circ}$, inciso VII, que a proteção de dados na sociedade da informação tem como fundamentos "os direitos humanos, o livre desenvolvimento da personalidade, a dignidade e o exercício da cidadania pelas pessoas naturais", o que demonstra a necessidade de o Estado intervir na esfera de interação social virtual para garantir o exercício destes direitos.

Ainda, das mudanças ocorridas no modelo estatal e na sociedade, destacase o surgimento e também a concretização de princípios voltados à proteção do indivíduo em sua esfera mais íntima, conforme será demonstrado em tópico próprio. Este Estado Democrático mostrou-se preocupado com os direitos fundamentais e, por esta razão, reconheceu que a dignidade deve "ocupar o lugar central no

${ }^{5}$ Lei 12.965 de 2014, a qual estabelece princípios, garantias, direitos e deveres para o uso da Internet no Brasil. 


\section{Personalidade Acadêmica Homenageada:}

Florisbal de Souza Del'Olmo (Professor Convidado - UNICURITIBA)

pensamento político, jurídico e filosófico, diante das incertezas das apreciações morais, no mundo contemporâneo [...]" (GOMES, 2005, p. 64), incluindo, nos dias de hoje, a atuação em ambiente virtual.

"O princípio da dignidade da pessoa humana é a expressão normativa do valor fundamental do ser humano na ordem jurídica brasileira" (AMARAL, 2008, p. 70) e serve de condão interpretativo para todo o sistema normativo, não apenas ao texto constitucional, vez que a dignidade está presente em todas as esferas da vida do cidadão, inclusive em suas manifestações e intenções na sociedade da informação.

\section{DIREITOS DA PERSONALIDADE}

Os direitos da personalidade estão diretamente ligados aos direitos fundamentais, e consequentemente, ao princípio da dignidade humana. A sua ligação com os direitos fundamentais dá-se tanto pelo fato de terem suas raízes na cultura grega quanto ao fato de que com o passar dos anos foram devidamente constitucionalizados. (DINIZ, 2011, p. 132)

Não apenas na Constituição de 1988 foram elencados os direitos da personalidade. O Código Civil de 2002 reservou o Capítulo II do Livro I para deles tratar. De acordo com 0 art. $11^{6}$ do referido código, estes direitos são intransmissíveis e irrenunciáveis, pelo que se pode concluir que são prerrogativas próprias dos seres humanos. "Na perspectiva do direito constitucional, são espécies do gênero direitos fundamentais. Na perspectiva do direito civil, constituem o conjunto de direitos inerentes da pessoa [...]". (LOBO, 2009, p. 143)

Os direitos da personalidade, também chamados de direitos personalíssimos, possuem características idênticas aos direitos fundamentais, já explicitados neste trabalho. Francisco Amaral (2008, p. 283) ensina que os "direitos

\footnotetext{
${ }^{6}$ Código Civil - Art. 11 Com exceção dos casos previstos em lei, os direitos da personalidade são intransmissíveis e irrenunciáveis, não podendo o seu exercício sofrer limitação voluntária.
} 


\section{Personalidade Acadêmica Homenageada: \\ Florisbal de Souza Del'Olmo (Professor Convidado - UNICURITIBA)}

da personalidade são direitos subjetivos que têm por objeto os bens e valores essenciais da pessoa, no seu aspecto físico, moral e intelectual".

Vale destacar que todo direito da personalidade é considerado direito fundamental, mas nem todo direito fundamental é tido como personalíssimo, vez que aqueles tutelam também direitos sociais, econômicos e culturais, tendo assim uma abrangência mais ampla. (LOBO, 2009, p. 137)

A correlação com o princípio da dignidade se dá pelo fato de que, como já demonstrado em tópico específico, esta prerrogativa é a base norteadora do sistema legislativo brasileiro. Atinge e rege, deste modo, não apenas normas constitucionais, mas também aquelas tidas como infraconstitucionais.

Cumpre, porém, antes de exemplificá-los, fazer referência a algumas características destes direitos. Além da intransmissibilidade e da irrenunciabilidade que estão devidamente expressas no Código Civil, Francisco Amaral (2008, p. 285) expõe:

\footnotetext{
Caracterizam-se os direitos da personalidade por serem essenciais, inatos e permanentes, no sentido de que, sem eles, não se configura a personalidade, nascendo com a pessoa e acompanhando-a por toda a existência. São inerentes à pessoa, intransmissíveis, inseparáveis do titular, e por isso se chamam, também, personalíssimos, pelo que se extinguem com a morte do titular. Consequentemente são absolutos, indisponíveis, irrenunciáveis, imprescritíveis e extrapatrimoniais.
}

Percebe-se pela citação, que os direitos da personalidade têm papel de destaque no ordenamento, pois pertencem ao indivíduo desde a sua concepção. Deste modo, o Estado não pode abster-se de protegê-los, devendo exercer medidas a fim de mantê-los intocáveis. Quanto à indisponibilidade, a lei abre exceções, vez que autoriza a disponibilidade de imagem, desde que autorizada pelo próprio indivíduo. A expansão virtual da vida, igualmente, também exige exceções aos conceitos clássicos, na medida em que o ambiente on-line se mostra mais propício para interações sociais e manifestações de opiniões livres, o que deve ser feito, no entanto, em constante observância às considerações éticas. 


\section{Personalidade Acadêmica Homenageada: \\ Florisbal de Souza Del'Olmo (Professor Convidado - UNICURITIBA)}

Os direitos da personalidade visam tutelar, como remete a própria nomenclatura, a personalidade do cidadão. Entende-se por personalidade o caráter ou qualidade do que é pessoal, a pessoalidade, o que determina a individualidade de uma pessoa moral, o elemento estável da conduta de uma pessoa ${ }^{7}$. "A personalidade não se identifica, portanto, com os direitos e as obrigações, mas se caracteriza como fundamento, funcionando como verdadeiro ponto de apoio daqueles". (SIMÓN, 2000, p. 61)

A Constituição, em seu art. 5ำ X, elenca alguns destes direitos:

Art. $5^{\circ}$ Todos são iguais perante a lei, sem distinção de qualquer natureza, garantindo-se aos brasileiros e aos estrangeiros residentes no País a inviolabilidade do direito à vida, à liberdade, à igualdade, à segurança e à propriedade, nos termos seguintes: [...] X - são invioláveis a intimidade, a vida privada, a honra e a imagem das pessoas, assegurado o direito a indenização pelo dano material ou moral decorrente de sua violação.

No âmbito da sociedade da informação, em que pese o espaço livre para manifestação de opinião, estas prerrogativas também são asseguradas, o que se verifica, inclusive, nas disposições preliminares da Lei 13.709, de 14 de agosto de 2018 referente á proteção de dados, a qual tem o“[...] objetivo de proteger os direitos fundamentais de liberdade e de privacidade e o livre desenvolvimento da personalidade da pessoa natural". (BRASIL, 2018)

O fato de ter como titular o indivíduo, faz que com sua proteção e aplicabilidade estendam-se também ao ambiente virtual, formando o grande desafio da atualidade, qual seja, o de preservar a dignidade e os direitos fundamentais mesmo com a ausência de barreiras da rede.

\subsection{DIREITOS DA PERSONALIDADE EM ESPÉCIE}

Cumpre apresentar no presente trabalho os direitos da personalidade que se referem à esfera íntima do indivíduo, vez que as ausências de barreiras explícitas no

\footnotetext{
${ }^{7}$ Definição de Personalidade no Dicionário Aurélio.
} 


\section{Personalidade Acadêmica Homenageada: \\ Florisbal de Souza Del'Olmo (Professor Convidado - UNICURITIBA)}

ambiente virtual, podem propiciar a interferência de terceiros em domínios da vida privada.

Como demonstrado anteriormente, os direitos personalíssimos tutelam também a integridade física e intelectual do indivíduo, a qual visa proteger a liberdade de expressão, de autoria e de pensamento. Por serem direitos da personalidade, é válido lembrar que possuem um caráter extrapatrimonial, ou seja, buscam proteger a individualidade e os direitos inerentes ao homem e à sua personalidade.

O pressuposto teleológico de todo o sistema normativo brasileiro, que é a dignidade da pessoa humana, seria suficiente, por si só, para fazer eclodir uma rede de proteção dos direitos da personalidade no âmbito da relação de emprego, impedindo-se fossem perpetradas contra os empregados transgressões destinadas a limitar os direitos à intimidade, honra, vida privada, imagem. Por derradeiro, incolumidade física e psíquica (COGO, 2006, p. 41).

As prerrogativas apresentadas na citação acima estão devidamente constitucionalizadas no art. $5, \mathrm{X}$ da Constituição Federal. No entanto, é sabido que os direitos da personalidade, assim como os direitos fundamentais, podem ter seu rol taxativo ampliado de acordo com as necessidades e as transformações da sociedade. $\mathrm{O}$ direito à vida é considerado como o mais importante no ordenamento jurídico, vez que protegendo a vida do indivíduo, as demais prerrogativas terão razão para serem tuteladas.

Do mesmo, modo ampara-se a privacidade, que de acordo com o civilista Paulo Lobo (2009, p. 150), abrange os direitos à intimidade, à vida privada, ao sigilo e à imagem. Em igual sentido, José Afonso da Silva (2004, p. 205), ensina que a privacidade engloba "todas as manifestações da esfera íntima, privada e da personalidade". Tem-se assim que a privacidade é um conceito mais amplo se comparado com o da intimidade.

O ordenamento jurídico, ao constitucionalizar e proteger a privacidade almejou preservar o "direito a estar sozinho". O indivíduo, para que possa aprimorar e fortalecer sua personalidade, precisa de um ambiente capaz de Ihe proporcionar 


\section{Personalidade Acadêmica Homenageada: \\ Florisbal de Souza Del'Olmo (Professor Convidado - UNICURITIBA)}

tal crescimento. Assim, a privacidade está diretamente ligada à personalidade de cada um, e por isso, é "identificada com aquilo que a pessoa é, e não com o que ela tem". (LEWICKI, 2003, p. 87)

Fazendo uma análise entre a dicotomia vida privada e intimidade, ambos direitos pertencentes ao conceito de privacidade, tem-se que esta se insere naquela. Em linhas gerais, a tutela da vida privada busca resguardar determinadas situações do aparecimento público. Por sua vez a intimidade, como induz a própria nomenclatura, liga-se às situações mais restritas e particulares.

O direito à vida privada diz respeito ao ambiente familiar, e sua lesão resvala nos outros membros do grupo. O gosto pessoal, a intimidade do lar, as amizades, as preferências artísticas, literárias, sociais, gastronômicas, sexuais, as doenças por ventura existentes, medicamentos tomados, lugares frequentados, as pessoas com que conversa e sai, até o lixo produzido, interessam exclusivamente a cada indivíduo, devendo ficar fora da curiosidade, intromissão ou interferência de quem quer que seja. (LOBO, 2009, p. 151).

A doutrina atual ${ }^{8}$ é majoritária ao conceituar tais termos de forma separada, não os considerando como sinônimos. Isto se dá em razão do já referido inciso $X$, do art. $5^{\circ}$ da Constituição Federal que elencou os direitos da personalidade considerando-os diferentes uns dos outros. No entanto, mesmo que sejam conceituados de maneira diversa eles estão diretamente ligados. René Ariel Dotti (2000, p. 74) aduz sobre esta ligação:

Para Dotti, a vida privada contém a intimidade: a primeira seria "o direito que a pessoa humana pode reivindicar para não ser absorvida pela massa", enquanto a segunda se consubstanciaria "numa zona reservada, (...) esfera de sentimentos da pessoa na qual ninguém poderia penetrar sem consentimento.

Entende-se por intimidade a "zona espiritual íntima e reservada de uma pessoa" (DINIZ, 2011, p. 152). Esta prerrogativa busca preservar a dignidade da

\footnotetext{
${ }^{8}$ A exemplo cita-se Alice Monteiro de Barros, Paulo Lobo, Sandra Lia Simón.
} 


\section{Personalidade Acadêmica Homenageada:}

Florisbal de Souza Del'Olmo (Professor Convidado - UNICURITIBA)

pessoa humana vez que trata diretamente do indivíduo e daquilo que ele deseja preservar do conhecimento dos demais.

Tem-se registrado que a primeira grande influência para o estudo do "direito à intimidade" está em um artigo escrito e publicado por Samuel Warren e Louis Brandeis em 1890. Para estes autores, foi preciso separar tal prerrogativa do direito à propriedade, a fim de dar o devido valor a liberdade individual e a inviolabilidade da personalidade humana. (SIMON, 2000, p. 72)

Muitos são os conceitos atribuídos ao termo intimidade. Ela está presente tanto no âmbito mais interno e particular de cada um, quanto na vida familiar e no âmbito externo, englobando também o ambiente virtual e as redes sociais.

Destarte, em uma análise geral a respeito do significado de tal privilégio considera-se o direito à intimidade como sendo aquele "direito a não ser conhecido em certos aspectos pelos demais. É o direito ao segredo, a que os demais não saibam o que somos ou o que fazemos". (BARROS, 1997, p. 29)

O fato de o ordenamento jurídico brasileiro ter a dignidade como sua fonte norteadora, faz com que os direitos individuais dos cidadãos sejam preservados em seu caráter absoluto, e por esta razão, são tidos como cláusulas pétreas. Ter a intimidade protegida constitucionalmente, reflete no modo com que relações particulares são firmadas.

Neste viés, e considerando as transformações atuais da sociedade, a Lei 13.709, de 14 de agosto de 2018, em seu artigo $2^{\circ}$, dispõe os fundamentos que disciplinam a proteção de dados, incluindo, além da dignidade, I - o respeito à privacidade; [...] e IV - a inviolabilidade da intimidade, da honra e da imagem.

Deve-se observar que por ser um direito inerente ao ser humano em sua essência, seus limites de proteção deverão ser mantidos em destaque. No âmbito atual da sociedade da informação, conforme será demonstrado, não raras vezes, a ausência de barreiras pode invadir espaços íntimos e privados do indivíduo, merecendo a regulamentação adequada por parte do Estado. 


\section{Personalidade Acadêmica Homenageada:}

Florisbal de Souza Del'Olmo (Professor Convidado - UNICURITIBA)

\section{INTERNET E REDES SOCIAIS}

A Internet deriva da difusão ampla de tecnologia gerada para se implantar uma rede de computadores, encomendada no final da década de 60 a alguns grupos de pesquisa de universidades americanas, pelo Departamento de Defesa dos EUA. Esta tecnologia se espalhou primeiramente pelo meio acadêmico nos Estados Unidos, após para todo o país e em seguida para o exterior. (TAKAHASHI, 2010, 133)

Internet é a rede que permite a troca de informações de forma surpreendentemente simples, rápida e com plena interatividade entre as pontas. (VIEIRA, 2007, p. 164)

Manuel Castells (2003, p.8), afirma que "A Internet é um meio de comunicação que permite, pela primeira vez, a comunicação de muitos com muitos, num momento escolhido, em escala global."

No Brasil, em 1988, através da Fundação de Amparo à Pesquisa do Estado de São Paulo (Fapesp), em parceria com a Secretaria Estadual de Ciência e Tecnologia, e apoio do centro de pesquisa dos Estados Unidos, Fermilab (Fermi National Accelerator Laboratory $^{9}$ ), ocorreu a primeira conexão à rede no país. Em 1992, o Governo Federal criou a Rede Nacional de Pesquisa (RNP) e, passou a investir em infraestrutura para facilitar o acesso à rede mundial de computadores no país.

Entre 1990 e 1995 a internet se popularizou, em grande parte graças ao desenvolvimento dos computadores pessoais, dos navegadores e sistemas desenvolvidos. Uma nova tecnologia criada influenciava o desenvolvimento de outra. O microprocessador desencadeou o desenvolvimento dos microcomputadores, os avanços em telecomunicações permitiram que os microcomputadores se interligassem em rede, incentivando o desenvolvimento de softwares (programas de computador, aplicativos) na busca de tecnologias que facilitassem a vida dos

\footnotetext{
${ }^{9}$ Laboratório Nacional de Aceleração de Fermi
} 


\section{Personalidade Acadêmica Homenageada:}

Florisbal de Souza Del'Olmo (Professor Convidado - UNICURITIBA)

usurários, e assim por diante, formando uma rede mundial de intercomunicação, fazendo da virtualidade algo real na vida dos indivíduos. (CASTELLS, 1999, p. 91)

No Brasil, a internet comercial teve início a partir de 1995, resultando em uma maior interatividade dos indivíduos, surgindo a Sociedade da Informação: uma sociedade digital, em rede, onde o real e virtual se confundem, se completam e se expandem. (PINHEIRO, 2010, p. 59-61)

A busca pela informação de forma imediata é um dos anseios dessa sociedade digital, ocorrendo o fenômeno chamado mutstasking, ou seja, a ação de fazer várias coisas ao mesmo tempo, de acessar diversas informações de forma simultânea (por exemplo, se conectar as redes sociais, assistir um vídeo, checar o email, ler uma notícia, etc.), passando a representar a rotina de grande parte das pessoas que passam o dia em frente a um computador. (LEMOS, 2002, p. 257)

Essa rotina desencadeia outro fenômeno: a cultura da auto-exposição, pois para existirem digitalmente, as pessoas passam a se expor na rede sem considerar as consequências que esse tipo de comportamento pode acarretar.

A necessidade do indivíduo de ser e se manter informado sobre tudo, inclusive fatos da vida alheia, materializa a visão de sociedade do espetáculo, onde é preciso ser visto para existir.

As pessoas colocam os seus dados em sites de redes sociais, podendo ser o Facebook, Linkedin ou outros que existem na internet conforme o país, sendo que as redes sociais mais dominantes globalmente são Facebok, Twitter, Odnoklassniki (russa), Vkontakte (russa) e Weibo (chinesa). Ainda, existem outras redes sociais menores, tais como o VK na Europa, o Cloob no Irã (neste país não existem usuários do Facebook). Na China, o buscador mais usado não é o Google e sim o Baidu e em vez do Youtube, usam o Youku e em vez do Whatsapp é o Wechat. (PINO; GONÇALVES, 2017, p. 15)

Manuel Castells (1999, p. 445) dispõe sobre a importância das redes sociais no contexto da interação social e das comunidades virtuais e, referindo-se a estas últimas, diz que "a internet favorece a expansão e a intensidade dessas centenas de laços fracos que geram uma camada fundamental da interação social para as 


\section{Personalidade Acadêmica Homenageada:}

Florisbal de Souza Del'Olmo (Professor Convidado - UNICURITIBA)

pessoas que vivem num mundo tecnologicamente desenvolvido". Afirma que as comunidades sociais são e não são reais, pois são comunidades, mas não são comunidades físicas, eis que não seguem a mesma forma de interação e comunicação destas. Completa, que não são irreais, mas que apenas funcionam em outro plano da realidade: "São redes sociais interpessoais, em sua maioria baseadas em laços fracos, diversificadíssimas e especializadíssimas, também capazes de gerar reciprocidade e apoio por intermédio da dinâmica da interação sustentada".

Contudo, o principal componente, o principal autor da rede social, é o indivíduo, que a alimenta com seus dados, preferências, interesses e afinidades.

\subsection{ATORES E CONEXÕES}

Raquel Recuero (2009, p. 24) afirma que uma rede social na internet é definida como "um conjunto de dois elementos: atores (pessoas, instituições ou grupos; os nós da rede) e suas conexões (interações ou laços sociais) ".

Os atores são o primeiro elemento de uma rede social, que através da interação e da formação de laços sociais formam as suas estruturas sociais. Explica Recuero (2009, p. 28), que "através da observação das formas de identificações dos usuários na Internet, é possível perceber os atores e observar as interações e conexões entre eles".

Contudo, os atores são constituídos de maneira um pouco diferenciada na internet, pois, como dialoga Recuero, (2009, p. 35) "por causa do distanciamento entre os envolvidos na interação social, principal característica da comunicação mediada por computador, os atores não são imediatamente discerníveis". Completa dizendo que "neste caso, trabalha-se com representações dos atores sociais, ou com construções identitárias do ciberespaço".

Assim, perfis do Facebook, weblog, fotologs, etc. são pistas de um "eu" que poderá ser percebido pelos demais. São construções plurais de um sujeito, representando múltiplas facetas de sua identidade. 


\section{Personalidade Acadêmica Homenageada:}

Florisbal de Souza Del'Olmo (Professor Convidado - UNICURITIBA)

As conexões de uma rede social podem ser percebidas de diversas maneiras. Para Recuero (2009, p. 30) "em termos gerais, as conexões em uma rede social são constituídas dos laços sociais, que, por sua vez, são formados através da interação social entre os atores".

\subsection{SOCIEDADE DA INFORMAÇÃO}

A expressão sociedade da informação foi usada pela primeira vez, oficialmente, pelo presidente da Comissão Européia em 1993, Jacques Delors, no Conselho da Europa de Copenhague, para definir o ascendente uso da tecnologia da informação na economia, visando melhorar a prestação dos serviços públicos e a qualidade de vida dos cidadãos. (VIEIRA, 2007, p. 156)

Sociedade da informação é uma nova forma de organização social, política e econômica, que se utiliza maciçamente do uso de tecnologia da informação para, segundo Vieira (2007, p. 156) "coleta, produção, processamento, transmissão e armazenamento de informações."

Informação consiste em um dado ou conjunto de dados, processado ou não, em qualquer suporte, capaz de produzir conhecimento, podendo ser uma imagem, um som, um documento físico ou eletrônico, ou até mesmo, um dado isolado, sendo, portanto, o principal ativo da sociedade da informação, sendo indispensável a qualquer atividade. $O$ trabalho, a educação, a saúde, o lazer, a política, a economia, ou seja, tudo depende de informação, como explica Vieira (2007, p. 157). A informação impõe-se como condição determinante para o desenvolvimento econômico e cultural da sociedade, sendo utilizada como um mecanismo facilitador da coleta, produção, processamento, transmissão e armazenamento de dados.

Manuel Castells (2003, p. 67-70) ensina que se vive atualmente a revolução da tecnologia da informação, que induz a todos e a tudo a um padrão de descontinuidade nas bases materiais da economia, da sociedade e da cultura, pois abala amplamente os domínios da vida, difundindo-se celeremente pelo mundo. 


\title{
Personalidade Acadêmica Homenageada: \\ Florisbal de Souza Del'Olmo (Professor Convidado - UNICURITIBA)
}

Vieira (2007, p. 158) afirma que da sociedade da informação decorre o progresso, mas que essa sociedade se impõe com valores imateriais, dados, informação, conhecimento científico e tecnológico, que constituem a força que movimenta a formação e desenvolvimento sociais. Diz ainda que:

\begin{abstract}
Surgem daí a indústria e os serviços de informação que abrangem atividades de educação, pesquisa científica, fabricação de equipamentos e sistemas de informação e de comunicações, mercados e serviços financeiros, bibliotecas e bancos de dados eletrônicos, biotecnologia e indústria farmacêutica. (VIEIRA, 2007, p. 158).
\end{abstract}

Salienta ainda a autora que essa nova forma de organização "reside na expansão do próprio conceito de informação que abrange a imagem, a voz e todo e qualquer dado em formato digital". Vieira continua afirmando que segundo alguns estudiosos, a sociedade da informação seria uma oportunidade histórica de realização de direitos da cidadania, principalmente quanto a liberdade de informação e de expressão, por disporem de mais e dos melhores meios de expressão, criação, participação e interação, o que ampliaria a participação democrática. Em sentido contrário, outros autores afirmam que a sociedade da informação agrava o risco de aumentar as desigualdades sociais, justamente pelas condições de acesso ou não à informação, aumentando as diferenças e a distância entre as classes sociais mais pobres e os mais favorecidos. Pode ainda, aumentar a vigilância por parte do Estado sobre os indivíduos. (VIEIRA, 2007, p. 158-159)

Manuel Castells (2003, p. 128) entende que a tecnologia da informação deveria ser utilizada para o fortalecimento das democracias, ampliando a participação dos cidadãos na gestão dos recursos públicos, ou seja, ao invés dos governos se utilizarem da internet para vigiar as pessoas, as pessoas deveriam usar da rede para vigiar os governos, considerando, que teoricamente, o povo é soberano. Contudo, a maioria dos estudos e relatórios mostra, com exceção dos países escandinavos, que os governos usam os recursos tecnológicos como mecanismo de poder, para vigilância e controle dos indivíduos, e não como um instrumento de fortalecimento da democracia participativa. 


\section{Personalidade Acadêmica Homenageada:}

Florisbal de Souza Del'Olmo (Professor Convidado - UNICURITIBA)

Ainda, a informação atualmente é utilizada pelos capitalistas para alterar o modo de produção de riqueza, particularmente na área de marketing, para garantir o êxito nessa atual fase de desenvolvimento econômico. É chamado o novo petróleo, comparada à posição que este exercia no início do século passado. E se a informação é o novo petróleo, as bases de dados públicos são sua principal nascente, onde a iniciativa privada busca os mais diversos tipos de informação, o que faz surgir a necessidade de se limitar e gerir seu uso. (VIEIRA, 2007, p. 160)

Da mesma forma, o Estado vem investindo na tecnologia da informação como forma de se modernizar e diminuir a burocracia, reduzir custos, dar mais transparência aos gastos públicos, incrementar a prestação de serviços e o relacionamento entre os cidadãos e a administração pública. Passa a utilizar-se de serviços on-line, como fornecimento de certidão, diário oficial eletrônico, pagamento e consulta on-line do fisco; pregão eletrônico; peticionamento eletrônico; portais de informações; gestão das chamadas infraestruturas críticas do país, como energia, água, transporte, telefonia e saneamento urbano. Contudo, essa maciça utilização de recursos da tecnologia da informação gera vulnerabilidades, ou seja, a possibilidade de falhas dos sistemas por ataques cibernéticos, por hackers ${ }^{10}$ ou crackers $^{11}$ ou grupos criminosos. (VIEIRA, 2007, P. 162-163)

Cresce, portanto, os denominados cybers crimes, crimes realizados por meio eletrônico, tanto na esfera pública, como privada.

Contudo, não é somente na esfera criminal que os dados e informações são utilizados sem autorização ou sequer, conhecimento do indivíduo. No âmbito privado, as empresas se valem dos dados alimentados na rede, para fins comerciais e interesses próprios.

\subsection{INVASÃO DE PRIVACIDADE NO ÂMBITO PRIVADO}

\footnotetext{
${ }^{10}$ Hacker é a pessoa que acessa sistemas informatizados sem autorização.

${ }^{11}$ Cracker é a pessoa que acessa sistemas informatizados sem autorização e com a finalidade de alterar ou remover dados.
} 


\section{Personalidade Acadêmica Homenageada:}

Florisbal de Souza Del'Olmo (Professor Convidado - UNICURITIBA)

Os indivíduos passam muito tempo conectados à internet, seja através de computadores, tablets ou smartphones, tanto em suas residências como em seus trabalhos.

As interações, tanto em redes sociais, como de serviços públicos ou privados utilizados, deixam rastros na internet, e essas interações permanecem no ciberespaço mesmo depois de "supostamente" deletadas. E desses rastros, que geram informações, várias empresas se aproveitam, mesmo sem autorização de seus autores.

Vieira (2007, p.155) ensina que "O avanço tecnológico, ao propiciar o cruzamento de dados pessoais e o monitoramento eletrônico de indivíduos e empresas, agiganta-se como uma ameaça ao direito à privacidade". As interações na internet deixam rastros, seja através do perfil das redes sociais às quais o indivíduo se conecta, seja pelas postagens que realiza, pesquisas, compras, serviços que utiliza, ou seja, todo tipo de interações praticadas.

Toda essa possibilidade de interação, não apresenta somente pontos positivos, mas também atrai insegurança e violação de direitos e da liberdade. É comum ter-se notícia de vazamentos de informações, de imagens, de notícias falsas, que causam graves impactos, como danos à reputação e à vida das pessoas, sendo que o principal risco relacionado às redes sociais é a invasão de privacidade e a ofensa à dignidade.

As empresas que atuam na rede buscam informações, onde a coleta de dados dos usuários é muito comum, acontecendo na maioria das vezes sem autorização, ou quando autorizada, é trocada por brindes, produtos ou serviços ofertados ao internauta. Surge então um problema na sociedade digital: a privacidade é totalmente invadida ou se torna uma moeda de troca, sendo que, não raras às vezes, tal invasão impacta diretamente na preservação da dignidade.

As empresas que prestam serviços pela internet e que têm como principal fonte de renda o marketing, monitoram constantemente seus usuários, utilizando-se de suas informações, vendendo-as para outras empresas ou traçando o perfil do 


\section{Personalidade Acadêmica Homenageada:}

Florisbal de Souza Del'Olmo (Professor Convidado - UNICURITIBA)

consumidor para obter alguma vantagem comercial, como oferecer produtos e serviços afins aos dados coletados na rede. (CASTELLS, 2003, p. 66-67)

Poucos serviços prestados na internet dispensam a coleta, o armazenamento, o tratamento e a difusão de dados relacionados com a intimidade e a vida privada dos internautas, pois todo acesso deixa registrado os dados do usuário, o seu espectro de relações, suas opiniões e gostos, os hábitos de consumo, o nível social, entre outros. O grande problema está no fato de a angariação de dados se dar tanto de forma transparente e autorizada pelo titular, como também de forma velada e contra os interesses do indivíduo. (VIEIRA, 2007, P. 176)

No ambiente de trabalho, as empresas controlam o uso dos sistemas de informática pelos empregados, utilizando-se de softwares (programas) que registram e arquivam seus acessos e consultas virtuais, objetivando tanto controlar o tempo, a produtividade e a maneira como realiza suas atividades, mas podendo utilizar-se do perfil desses empregados, para fins comerciais. (VIEIRA, 2007, P. 176-177)

Assim, as informações pessoais contidas em diferentes bancos de dados, tanto privados como públicos, e até do ambiente de trabalho, são interconectados como forma de facilitar a manipulação dos consumidores.

Um exemplo recente de violação à privacidade foi o escândalo de comercialização de dados envolvendo o Facebook, quando uma empresa parceira obteve dados pessoais de mais de cinquenta milhões de usuários e os utilizou para o direcionamento personalizado de mensagens e propagandas políticas nas últimas eleições dos Estados Unidos da América. O intuito específico da empresa parceira foi "compilar perfis psicométricos que classificam as pessoas por tipo de personalidade, de modo a que pudesse encaminhar a elas mensagens políticas com maior probabilidade de influenciar suas decisões". (HUCHLER, 2018)

O caso gerou um escândalo global na rede social citada, pois, a mesma empresa pode estar envolvida com repercussões políticas em outros países.

De acordo com a reportagem do Jornal Folha de São Paulo, de 25 de março de 2018, editada por Hannah Huchler, o funcionamento do Facebook tem como 


\section{Personalidade Acadêmica Homenageada:}

Florisbal de Souza Del'Olmo (Professor Convidado - UNICURITIBA)

modelo de negócio a publicidade direcionada aos seus usuários, com pouca atenção à proteção da privacidade de seus membros.

Este modelo não é exclusividade do Facebook. Outra empresa que o utiliza é o Google, com constante vigilância sobre o comportamento dos usuários na internet, observando o que se pesquisa na rede, localização da pessoa, compras, comentários, relacionamentos, dentre outras inúmeras possibilidades de armazenamento de dados que possam melhor estruturar a formação de um perfil sobre a personalidade do indivíduo, e dessa forma lhe direcionar a publicidade de seus clientes anunciantes.

Diante do desenvolvimento tecnológico hoje existente, os riscos à dignidade, à privacidade e à intimidade nunca foram tão agudos e tão consistentes, sendo necessário cada vez mais buscar garantias contra tais invasões e impor limites às atuações virtuais, utilizando-se da legislação já existente, como exposto no capítulo anterior.

\section{CONCLUSÃO}

$\mathrm{Na}$ atual sociedade cibernética, a utilização da tecnologia se amplia diuturnamente, tanto pelos indivíduos, quanto pelo Estado.

Surge a sociedade da informação, uma nova forma de organização social, política e econômica, que se utiliza maciçamente do uso de tecnologia da informação para coleta, produção, processamento, transmissão e armazenamento de informações. Essa nova forma de organização reside na expansão do próprio conceito de informação que abrange a imagem, a voz e todo e qualquer dado em formato digital.

As pessoas alimentam a sociedade da informação, pois passam cada vez mais tempo conectadas à internet, expondo-se em redes sociais, utilizando-se do mundo virtual de diversas formas, como para pesquisa, consultas, compras, 


\section{Personalidade Acadêmica Homenageada:}

Florisbal de Souza Del'Olmo (Professor Convidado - UNICURITIBA)

serviços, etc. Da mesma forma, Estado também alimenta essa nova sociedade, pois se utiliza cada vez mais da tecnologia para realizar a prestação de serviços aos cidadãos, como emissão de certidões, consultas e pagamentos ao fisco, diário oficial eletrônico, serviços de energia, água, transporte, entre tantos outros.

Há tantos benefícios quanto malefícios na sociedade da informação. Alguns autores a encaram como uma oportunidade única de realização de direitos da cidadania, por poderem dispor dos meios de expressão, criação, participação e interação, o que ampliaria a participação democrática, inclusive na gestão de recursos públicos. Outros autores ressaltam o lado negativo, dizendo que a sociedade da informação agrava o risco de aumentar as desigualdades sociais, justamente pelas condições de acesso ou não, á informação, aumentando as diferenças e a distância entre as classes sociais, bem como pode aumentar a vigilância do Estado sobre os indivíduos.

Contudo, todas essas interações, tanto dos indivíduos como do Estado, deixam rastros na internet, ou seja, ficam registrados na rede os acessos, as conexões, os dados pessoais, as pesquisas, consultas, compras, etc., e a maciça utilização dos recursos tecnológicos, gera vulnerabilidades, como ataques cibernéticos por hackers, crackers ou organizações criminosas, mas principalmente, a violação da privacidade.

A privacidade e a intimidade são consideradas direitos fundamentais, inseridas na carta constitucional e diretamente ligadas ao princípio da dignidade da pessoa humana, princípio esse consagrado na Declaração de Direitos Humanos.

Com o avanço tecnológico, esses direitos têm sido cada vez mais violados, tanto por parte do Estado, para vigilância e manutenção do poder sobre os indivíduos, tanto pelas empresas privadas, que se valem dos dados alimentados na rede, para fins comerciais, visando o lucro, formando o perfil do consumidor para the enviar publicidade.

E onde está o limite para essa invasão da privacidade?

$\mathrm{Na}$ legislação pátria, o direito à privacidade e à intimidade é previsto no artigo 5o, X, da Constituição Federal, no artigo 11 do Código Civil, na Lei 
Personalidade Acadêmica Homenageada:

Florisbal de Souza Del'Olmo (Professor Convidado - UNICURITIBA)

12965/2014, considerada o marco civil da internet, e a recente Lei 13709/2018, sobre a proteção de dados.

Entretanto, faz-se necessário também, uma maior divulgação aos cidadãos, de seu direito à privacidade, bem como uma conscientização para que não se exponham demasiadamente nas redes sociais, e que tenham bom senso na utilização da rede.

Ainda, necessário que exista a possibilidade do completo cancelamento ou apagamento de todas as informações pessoais pertinentes ao usuário da rede, configurando assim, a manutenção à dignidade e a proteção ao direito à privacidade, bem como o consentimento sobre a exposição dos próprios dados.

\section{REFERÊNCIAS}

BARROS, Alice Monteiro de. Proteção à Intimidade do Empregado. São Paulo: LTr, 1997.

BESTER, Gisela Maria. Direito Constitucional - volume I. São Paulo: Manole, 2005.

BOBBIO, Norberto. A era dos direitos. Rio de Janeiro: Campos, 1992.

BRASIL 1988. Constituição da República Federativa do Brasil. Disponível em: <http://www.planalto.gov.br> Acesso em: 1 set. 2018.

. 2002. Lei 10.406 de 10 de janeiro de 2002. Código Civil Brasileiro. Disponível em: <http://www.planalto.gov.br>. Acesso em: 1 set. 2018.

2018. Lei 13.709 de 14 de agosto de 2018. Dispõe sobre a proteção de dados pessoais e altera a Lei no 12.965, de 23 de abril de 2014 (Marco Civil da Internet). Disponível em: <http://www.planalto.gov.br>. Acesso em: 1 set. 2018.

CASTELLS, Manuel. A sociedade em Rede: A era da informação: economia, sociedadee cultura, Vol. 1. São Paulo: Paz e Terra, 1999.

A Galáxia da Internet: Reflexões sobre a Internet, os negócios e a sociedade. Rio de Janeiro: Jorge Zahar Editor, 2003.

COGO, Sandra Negri. Gestão de pessoas e a integridade psicológica do trabalhador. São Paulo: LTr, 2006. 
Personalidade Acadêmica Homenageada:

Florisbal de Souza Del'OImo (Professor Convidado - UNICURITIBA)

DINIZ, Maria Helena. Curso de Direito Civil Brasileiro: teoria geral do direito civil. São Paulo: Saraiva, 2011.

DOTTI, René Ariel apud SIMÓN, Sandra Lia. A Proteção Constitucional da Intimidade e da Vida Privada do Empregado. São Paulo: LTr, 2000.

GOMES, Dinaura Godinho Pimentel. Direito do Trabalho, Dignidade da Pessoa Humana, no contexto da globalização econômica. São Paulo: LTr, 2005.

KUCHLER, Hannah. Escândalo ameaça modelo do Facebook. Jornal Folha de São Paulo. 2018. Disponível em: <https://www1.folha.uol.com.br/mercado/2018/03/escandalo-ameaca-modelodofacebook.shtml >. Acesso em: 7 set. 2018.

LEMOS, André. Cibercultura: tecnologia e vida social na cultura contemporânea. Porto Alegre: Sulina, 2002.

MARTINS, Flademir Jerônimo Belinati. Dignidade da Pessoa Humana. Curitiba: Juruá, 2006.

PAROSKI, Mauro Vasni. Direitos Fundamentais e Acesso à Justiça na Constituição. São Paulo: LTr, 2008.

PINHEIRO, Patrícia Peck. Direito Digital. São Paulo: Saraiva, 2010.

PINO, Martim Manuel; GONÇALVES, Diego Marques. Os direitos à intimidade e à privacidade em face aos mecanismos de coleta de dados pessoais na rede mundial de computadores. In: PIDCC, Aracaju, Ano VI, Volume 11 no 03, p.001 a 020 Out/2017. Disponível em: <http://pidcc.com.br/artigos/102017/01102017.pdf>. Acesso em: 7 set. 2018.

RECUERO, Raquel. Redes sociais na internet. Porto Alegre: Sulina, 2009.

SARLET, Ingo Wolfgang. A eficácia dos Direitos Fundamentais - uma teoria geral dos direitos fundamentais na perspectiva constitucional. 10. ed. Porto Alegre: Livraria do Advogado, 2010.

Dignidade da Pessoa Humana e Direitos Fundamentais. Porto Alegre: Livraria do Advogado, 2006.

SCHIMITT, Carl. Verfassungslehre. pp. 163/177 IN: BONAVIDES, Paulo. Curso de Direito Constitucional. São Paulo: Malheiros, 2005. 
Personalidade Acadêmica Homenageada:

Florisbal de Souza Del'Olmo (Professor Convidado - UNICURITIBA)

SILVA, José Afonso da. Curso de Direito Constitucional Positivo. São Paulo: Malheiros, 2004.

TAKAHASHI, Tadao (Org.). Sociedade da informação no Brasil: livro verde. Brasília: Ministério da Ciência e Tecnologia, 2000.

VIEIRA, Tatiana Malta. $O$ direito à privacidade na sociedade da informação: efetividade desse direito fundamental diante dos avanços da tecnologia da informação. Porto Alegre: Sergio Fabris, 2007. 